\title{
Understanding the Complexity of Regional Innovation Capacity Dynamics in China: From the Perspective of Hidden Markov Model
}

\author{
Shuai Liu ${ }^{1,+}$, Xiao-Yu Xu $^{1,+}{ }^{+}$, Kai Zhao ${ }^{1, * \mathbb{C}}$, Li-Ming Xiao ${ }^{2}$ and Qi Li ${ }^{1}$ \\ 1 School of Economics and Finance, Xi'an Jiaotong University, Xi'an 710061, China; \\ shuailiu@stu.xjtu.edu.cn (S.L.); xuxiaoyu@xjtu.edu.cn (X.-Y.X.); liq@xjtu.edu.cn (Q.L.) \\ 2 School of Economics and Management, Shanxi Normal University, Linfen 041000, China; \\ xiaolm1972@sxnu.edu.cn \\ * Correspondence: kaizhao@mail.xjtu.edu.cn \\ + These authors contributed equally to this article.
}

Citation: Liu, S.; Xu, X.-Y.; Zhao, K.; Xiao, L.-M.; Li, Q. Understanding the Complexity of Regional Innovation Capacity Dynamics in China: From the Perspective of Hidden Markov Model. Sustainability 2021, 13, 1658. https://doi.org/10.3390/su13041658

Academic Editor: João J. Ferreira

Received: 17 December 2020

Accepted: 30 January 2021

Published: 4 February 2021

Publisher's Note: MDPI stays neutral with regard to jurisdictional claims in published maps and institutional affiliations.

Copyright: () 2021 by the authors. Licensee MDPI, Basel, Switzerland. This article is an open access article distributed under the terms and conditions of the Creative Commons Attribution (CC BY) license (https:// creativecommons.org/licenses/by/ $4.0 /)$.

\begin{abstract}
This study aimed to explore the state transition of regional innovation capacity (RIC) and analyze the heterogeneous effects of determinants in an innovative subject and environment of RIC state transition based on the data collected from 30 provinces in China during 2000-2017. By applying a hidden Markov model (HMM), this study identified three RIC states: low, medium, and high. The results suggested that (1) the overall state of RIC rapidly improved but with a significant disparity across regions in China; (2) the lock-in effect of RIC is most significant in regions with a medium state, while the enterprise-dominated mode of regional innovation helps RIC transition from a medium state to a high state or to remain in a high state; and (3) the interaction and collaboration between universities and enterprises in a region can stimulate RIC to higher states for all regions. Intellectual property administrative protection exerts positive impacts on RIC transitions to higher states. Intellectual property judicial protection only exerts positive impacts on an RIC's transition from a medium state to a high state or remaining in a high state, while these positive impacts are not significant when RIC is in a low state. Highlighting the dynamic nature of RIC evolution and the heterogeneity of determinants affecting RIC state transition, the findings provide policymakers a roadmap to identify RIC states and make precise policies based on the current RIC state.
\end{abstract}

Keywords: regional innovation capacity; state transition process; hidden Markov model; innovation subject determinants; innovation environment determinants

\section{Introduction}

In light of the knowledge-based economy, one emerging concept that has gained popularity in regional economies is regional innovation capacity (RIC) [1]. RIC can be defined as the level of productivity or state of an innovation system, and it is determined by the efficiency of knowledge production and diffusion, as well as a learning environment where innovation-driven factors including universities, research institutes, and enterprises are highly intertwined [2]. The improvement of RIC is a powerful driving force and an important way to realize sustainable economic development [3]. RIC directly determines the performance of regional technological innovation [4]. Technological innovation can effectively balance economic development, resource consumption, and environmental issues, thus facilitating the sustainability of humanity, society, economy, and nature [5]. However, the present situation is that the global and national disparity in RIC is very significant and gradually expanding [6]. Similarly, the RIC in China is exhibiting a quite significant difference across regions compared to that of 40 years ago. With this in mind, the exploration of the dynamic transition process of RIC may provide useful knowledge to interpret the reasons behind such a heterogeneity [7] and facilitate a better understanding of the mechanism that shortens the gap across regions in terms of innovation capacity. 
Integrating endogenous growth theory, the theory of industrial competitive advantage, and research on national innovation system [8-10], Furman's framework proposed that the national innovation capacity mainly depends on the strength of a nation's common innovation infrastructure, the environment for innovation, and their interaction [11,12]. This seminal framework has been especially widely applied to investigate regional innovation capacity. Compared to national innovation capacity, RIC is easier to manage and coordinate communication and reciprocity among different "actors" who play larger roles in determining its networking quality $[11,13]$. Numerous indicators have been utilized to measure RIC [14], such as R\&D inputs, patent data, the number of new products, the number of high-tech employees, and research expenditures $[15,16]$, since these indicators are believed to reflect innovative efforts and the efficiency of an innovation process.

Most studies have mainly focused on investigating the notable features of (1) spatial disparity and (2) conditional convergence regarding RIC [17-20]. The disparity in RIC is commonly observable, as larger regions are more likely to receive benefits from "agglomeration" (e.g., larger markets, more efficient matching, and knowledge spillovers) than smaller ones to promote innovation [21]. Importantly, with the fine division of labor and improvements of transportation and communication systems, the spatial distribution and agglomeration of RIC have been undergoing great changes [22] that have shown the significantly dynamic nature [23]. Moreover, many studies have also suggested that RIC shows a trend of conditional convergence, in addition to the feature of spatial disparity [19,24-26]. For regions sharing similar characteristics (e.g., institutions, policies, and investments), their spatial disparity would diminish gradually.

However, neither the analytical framework of spatial disparity nor of the framework of conditional convergence considers the dynamic nature of RIC. The existing literature on innovation capacity research has mostly used static empirical methods, such as fixed effect stochastic frontier, and spatial econometric models [6,11,27], based on cross-national or cross-regional comparisons of innovation capacity at a fixed period $[17,19,28]$. Technological innovation is an inherently dynamic and nonlinear process over time [29]. Blundell et al. [30] indicated that the transition process of innovation capacity cannot be comprehensively explained in a linear trajectory, so its modeling and measurements should integrate the analysis of dynamic characteristics. In other words, the development of RIC may experience different states over time. For example, eastern China may continuously maintain a competitive RIC, while the RIC in other regions, such as the western regions, may be comparatively weak. However, a western region has the potential to transition to a more competitive state in a future period due to policy support, environmental changes, and growth rate fluctuations [25]. With this in mind, several studies have attempted to explore state transitions of RIC at different stages. However, researchers have so far lacked a specific objective to distinguish these RIC states using rigorous model estimation [4,31]. Hence, a reliable method incorporating dynamic estimations is expected to bring more insights regarding how an RIC dynamically evolves.

Second, Furman's framework was applied to investigate the determinants of national or regional innovation capacity, such as innovation inputs, innovation subjects, and innovation environments $[32,33]$. Practice has shown that innovation investment, interactions among innovation subjects, and innovation environments can effectively promote knowledge flow and cope with the increasing innovation cost risk and technology complexity, thus enhancing RIC and strengthening innovation sustainability [34]. For example, Li [27] suggested that the composition of innovation subjects, such as different proportions of enterprises, universities, and research institutes, explained the disparity in RIC across regions. Researchers have indicated that a region's RIC can receive benefits from the spatial agglomeration of human capital, since it can facilitate proximal, personal, and recurrent contacts and the exchange of non-codified and tacit knowledge [35,36]. Along this line of thought, RIC demonstrates the potential and capacity of a region to utilize innovation infrastructures and environments, as well as to eventually transfer creative ideas or innovation to concrete socio-economic outcomes at the sub-aggregate level. Due 
to the dynamic nature of RIC, the RIC development of a region may experience a transition process with several development states. However, existing results are not sufficient to explain how determinants exert different effects on RIC in different development states. Therefore, in association with the model-setting issues mentioned above, it is of great significance to analyze the heterogeneous effects of critical determinants on RIC from a dynamic perspective [37].

Addressing research gaps, this study endeavored to explore: (1) how the states of RIC change over time in China and (2) the determinants affecting the RIC in different transition states. To answer these questions, this study applied the hidden Markov model (HMM) to investigate the dynamic transition of RIC in China. The HMM provides a reliable approach to identify the transition states of RIC by mapping each RIC state as a hidden variable and using regional innovation input and output as measurement variables [38]. Additionally, the HMM explicitly defines the RIC state transition matrix, thus enabling the investigation of the dynamic transition process of RIC. Furthermore, the HMM facilitates the analysis of the determinants of RIC in different states based on the identification of the state sequence of RIC.

This study provides two main contributions to the literature on regional innovation. On one hand, using the HMM approach, this study shows scholars and practitioners a novel perspective to explore the complexity of RIC in China, and implications from the findings of this study are meaningful for policymakers in China or worldwide for a better understanding of the geographical blueprint of RIC and more precisely designing conforming policies. On the other hand, according to the authors' best knowledge, this study is also one of the earliest attempts to confirm that the effects of the determinants of an RIC vary not only across regions and over time but also across different stages of innovation development.

The rest of this paper is arranged as follows: the literature review is illustrated in Section 2, Section 3 introduces the HMM and describes the variables, Section 4 describes the current status of RIC state transitions and particularly discusses RIC state transition probability and the determinants of RIC state transition, Section 5 discusses the empirical results, and Section 6 concludes and shows managerial implications and research limitations.

\section{Research Background}

\subsection{Technological Innovation in China}

Since the reform and opening up in 1978, rapid development in terms of science, technology, and economy has been observed in China [39]. Specifically, China has made great effort in improving its innovation capacity. For instance, the total R\&D expenditure dramatically increased from 9 billion Chinese dollars in 1988 to 2.17 trillion Chinese dollars in 2019, ranking second in the world; the number of domestic invention patent applications increased from 4780 in 1988 to 1.4 million in 2019, ranking first in the world; and the contribution rate of technological progress, which comprehensively reflects the effect of innovation to economic growth, increased from $27 \%$ in 1985 to $52.2 \%$ in 2012 and then up to $59.5 \%$ in 2019. The report of World Intellectual Property Organization (WIPO) summarized that China's overall innovation capacity had risen to world number 17 in 2019.

With great financial and policy supports, as well as under the dominant milieu of global innovative (creative) development, China's innovation system has inevitably experienced tremendous changes. At the national or regional level, China's innovation system exhibits several notable features that are similar to other developing or transitional countries: (1) the adoption of diversified development models, i.e., learning, imitation, improvement, integration, and iteration are all effective innovative strategies; (2) private high-tech enterprises and central enterprises have played a jointly important role, and there is a tendency that colleges and universities are becoming the source of innovative knowledge and the incubator of innovations; and (3) there is an increasing variation in regional innovation performance, as innovation resources become gradually concentrated in a few highly innovative regions. 


\subsection{The Hidden Markov Model}

The hidden Markov model can be categorized as a hidden variable model that is mainly adopted to analyze the relationships among hidden variables, response variables, and the state transition of hidden variables [40]. The most notable feature of such a mixture model is that the distribution of observations at time $t$ is fully specified given a hidden state [41], and a hidden state within this model specification is assumed not to be independent but rather to have a Markovian structure [40], thus leading to a level of dependency between different sets of observations [42].

The HMM is utilized to make inferences or predictions about an unobserved process based on an observed process [43,44]. For example, the HMM has been successfully used for prediction in the field of business cycles [45]. In this context, the data regarding an observed economic performance can be modeled as a function of unobserved business cycles (such as recession and growth). Given the economic operation data of that year, the HMM predicts whether the current economy is in a state of recession or growth. The HMM can also be used in R\&D cooperation to facilitate small- and medium-sized enterprises in identifying technology fields most suitable for company development [46]. Moreover, the HMM provides an in-depth understanding of the transition rules and determinants of an unobserved process. For example, Chen et al. used a model of the HMM to study three motivating mechanisms, i.e., reciprocity, peer identity, and self-image that affect the transition of users' potential motivation states in an online community [47]. Singh et al. developed a model of the HMM to capture developer learning dynamics in open-source software projects [48].

\subsection{Measurements and Determinants of Regional Innovation Capacity}

Numerous indicators are used to measure a level of RIC [14], including R\&D inputs, the number of high-tech employees, research expenditures, patent data, and the number of new products $[15,16]$. These indicators mainly measure RIC from two aspects regarding innovation input and output $[49,50]$. First, due to the generality, consistency, and accessibility of patent quantities, the number of patents is a common index frequently used in the literature to measure innovation output [51]. The legal system of intellectual property rights protection is especially unified in China. Hence, patent data of different regions are highly comparable, since these patent data are documented using a unified statistical scope. There are three types of patents: invention patents, utility model patents, and design patents.

Second, input elements of regional innovation are mainly measured by knowledge stock and R\&D investment, such as the historical stock of knowledge, R\&D personnel, and venture capital. Based on the knowledge production function, the speed and quality of knowledge production depend on how these elements can be efficiently utilized within a knowledge-generation process $[18,52]$. It is worth mentioning that measuring knowledge stock appears to be difficult due to the immeasurability of knowledge [6], so it is often integrated with the labor force in an intangible form of two aspects: quality and scale. In comparison, the level of R\&D investment relates to capital input and labor input. Prior studies have widely suggested using capital stock as the measurement tool [53] to avoid the possible issue of multicollinearity, and both its present and lagging effects should be taken into consideration [27].

To understand the underlying drivers of an innovation transition and achieve long-run economic growth, the present literature explored determinants of RIC from two dimensions. The first was the cooperation mode and synergy degree among innovation subjects, such as enterprises, universities, and research institutes that substantially affect the regional innovation efficiency $[6,20,36]$. The effective cooperation of innovation subjects usually takes a long time to produce synergy. The second is an innovation environment that also plays a critical role in determining innovation development, including policy, financial, and education provisions [14]. Particularly, policy intervention has an additional role in facilitating $R \& D$ and innovation because the market alone cannot provide appropriate 
incentives for networking and knowledge production [33,54,55]. For instance, Singapore is known for strong government intervention in directly and indirectly encouraging the development of innovation [51].

However, despite the effort to include a range of factors reflecting the complexity associated with RIC, there is still room for advancement, especially in association with the "dynamic-context" of this concept. Grounded on Schumpeter's theory of disruptive innovation, the process of technological innovation is always dynamic and nonlinear [29]. Hence, the determinants of RIC may show different effects at different states of innovation capacity. With respect to this, the majority of studies to date have mainly taken static or linear approaches to explore the determinants of innovation capacity. For example, Furman et al. [11] used a fixed effect model to conquer the idiosyncratic country/year-specific technology shock, whereas the fixed effect model did not consider the dynamics of the innovation process. Li [27] applied a stochastic frontier model to investigate the disparity in innovation capacity across Chinese regions. In comparison, a spatial autoregressive negative binomial regression model [6] was employed to study heterogeneity of innovation capacity across urban, metro-adjacent rural, and remote rural counties, but again the time relevance of innovation capacity was still not taken into consideration.

In summary, we argue that RIC is attached to a complex and dynamic system that contains not only various static innovation-driven factors but also function mechanisms that facilitate these factors to flow, develop, and coordinate. In this sense, the present literature does not provide sufficient materials for understanding the complexity of RIC in the dynamic context. Therefore, the authors of this paper attempted to investigate the relationship between RIC-driven factors and the state of RIC by developing an HMM framework that allows for the estimation of RIC state transition probability where determinants of RIC state transitions are randomized at different development stages and over time.

\section{Research Design}

\subsection{Hidden Markov Model for RIC}

With a hidden nature, RIC is difficult to directly measure or observe. Therefore, traditional econometric models commonly use proxy variables including R\&D capital, R\&D personnel, or patent quantity $[3,55,56]$ as a replacement. These approaches, to a certain extent, allow scholars to capture RIC characteristics that are only based on a static and simplex model structure and cannot further reveal the internal dynamic process among innovation-driven factors. In comparison, the HMM provides a solution for these issues that further conceptualizes the process of RIC development as a set of dynamic interactions represented by a number of response variables generated by potential or hidden processes. With this in mind, the HMM allows us to simultaneously measure multiple RIC-related response variables, to explicitly characterize the dynamics of an RIC [38], and to analyze its determinants at different stages under a unified analytical framework.

Specifically, the HMM represents a stochastic process that consists of three interrelated aspects: a finite set of hidden states (hidden variable), observed outcomes (response variable) conditional on hidden states, and the probabilities of transitioning from one state to another (state transition matrix) [47]. The evolution of RIC hidden states is assumed to follow the structure of the RIC state transition matrix, and observed outcomes are modeled as being independently conditional on sequences of hidden states. Figure 1 graphically illustrates how an HMM models RIC transitions between different states by incorporating the effects of determinants (i.e., innovation subject and environment) and how an innovation probability can be related to a specific RIC state. In period $t$, a region probabilistically fits into an RIC state, 1 being the lowest RIC state and $n$ being the highest. The factors of the regional innovation subject and the innovation environment in $t$ determine whether a region will either move up to a higher state, stay where it is, or move down to a lower state in the next period $t+1$. Then, the specific RIC state of this region is confirmed in period $t+1$, which also probabilistically determines the general level of its 
innovation input and output. The construction and description of the HMM are presented in the subsections below.

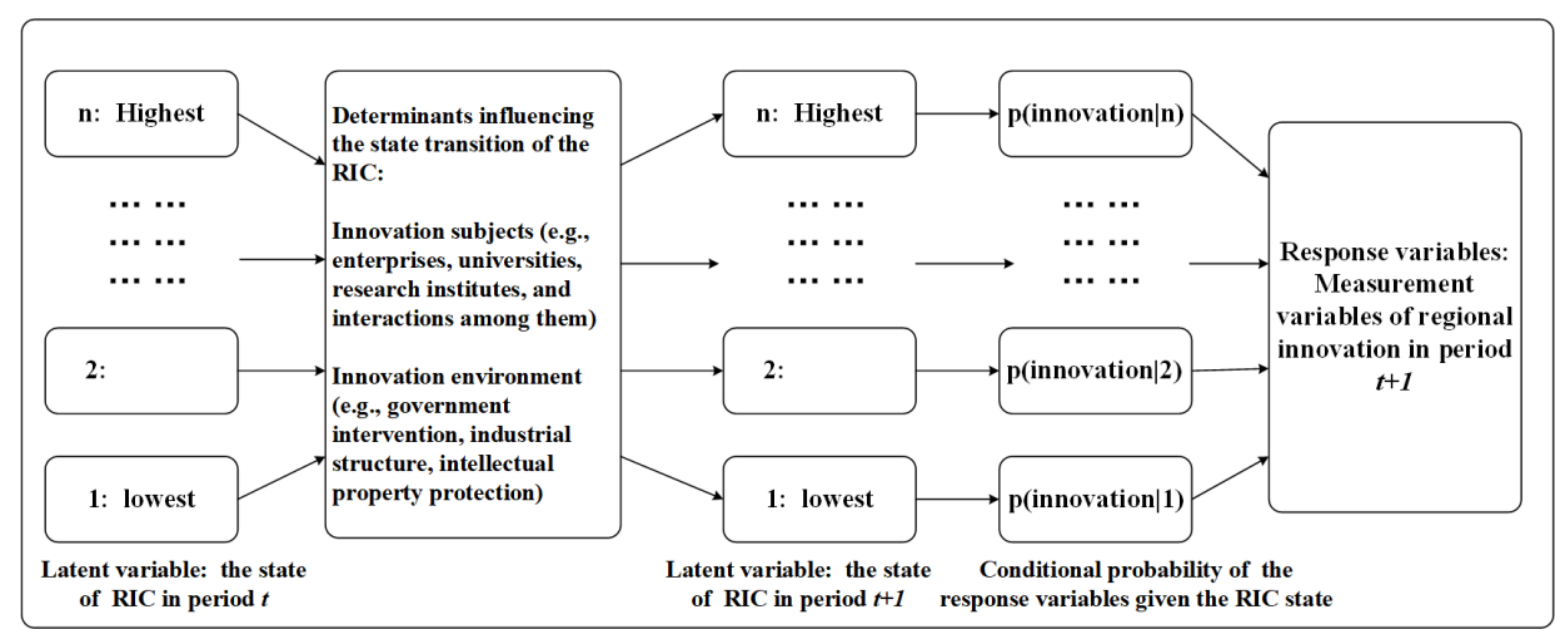

Figure 1. Hidden Markov model of regional innovation capacity (RIC).

\subsubsection{Model Specification}

Consider that the states of RIC belong to an aggregate $S=\{1,2, \cdots, n\}$. For a particular region $i, S(i)=S_{i 1} S_{i 2} \cdots S_{i t} \cdots S_{i T}$ is a finite hidden and unobservable state sequence, and $O(i)=O_{i 1} O_{i 2} \cdots O_{i t} \cdots O_{i T}$ is an observable sequence of response variables. $O_{i t}$ is the vector containing $r$ observable response variables at time $t$. Then, the conditional probability of the response variables $O(i)$, given the state sequence $S(i)$ and the parameter set $\beta$ to be estimated, is:

$$
P(O(i) \mid \beta, \mathrm{S}(i))=\prod_{t=1}^{T} P\left(O_{i t} \mid \lambda, S_{i t}\right)=a\left(O_{i 1} \mid S_{i 1}\right) \cdot a\left(O_{i 2} \mid S_{i 2}\right) \cdots a\left(O_{i T} \mid S_{i T}\right)
$$

where $a\left(O_{i t} \mid S_{i t}\right)$ is the probability of observing response variables $O_{i t}$ given that the region $i$ is in the state $S_{i t}$ at time $t$. For the RIC state sequence $S(i)$, the probability of its occurrence is:

$$
P(S(i) \mid \beta)=\pi(i) q\left(S_{i 1}, S_{i 2}\right) \cdots q\left(S_{i t}, S_{i t+1}\right) \cdots q\left(S_{i T-1}, S_{i T}\right)
$$

where $\pi(i)$ is the initial probability when RIC is at state $S_{i t}$ in period $t=1$, while $q\left(S_{i t}, S_{i t+1}\right)$ is the conditional probability when RIC is at state $S_{i t+1}$ in period $t+1$ given that it in state $S_{i t}$ in period $t . q\left(S_{i t}, S_{i t+1}\right)$ is an element of the RIC state transition matrix $Q(t, t+1)$. For region $i$, the likelihood function of the response variables sequence is shown as follows:

$$
L(O(i))=P(O(i) \mid \beta)=\sum P(O(i) \mid \beta, S(i)) P(S(i) \mid \beta), \forall S(i)
$$

When determinants are included in the general HMM by modeling RIC state transition, the main research interest is in modeling the effect of determinants on the distribution of RIC hidden states. The RIC state transition matrix is defined as follows:

$$
Q(t, t+1)=\left(\begin{array}{cccc}
q(1,1) & q(2,1) & \cdots & q(1, n) \\
q(2,1) & q(2,2) & \cdots & q(2, n) \\
\vdots & \vdots & \ddots & \vdots \\
q(n, 1) & q(n, 2) & \cdots & q(n, n)
\end{array}\right)
$$

where $q(j, k)=P\left(S_{t+1}=k \mid S_{t}=j\right), \sum_{k=1}^{n} q(j, k)=1,0 \leq q(j, k) \leq 1 \forall j, k \in\{1,2, \cdots, n\}$. Considering the discrete characteristic and polymorphism of the RIC state, this study assumed that the RIC state transition probability followed a multinomial logit model to explore determinants of RIC state transition [41]; the effect of these factors on RIC was 
allowed to be state-varying, so heterogeneous effects of determinants on RIC state transition could be evaluated from a dynamic perspective. The model is presented as follows:

$$
\begin{gathered}
\log \frac{p\left(S_{i 1}=k \mid X_{i 1}=x_{i 1}\right)}{p\left(S_{i 1}=1 \mid X_{i 1}=x_{i 1}\right)}=\beta_{0 k}+x_{i 1} \beta_{1 k}, k \geq 2 \\
\log \frac{p\left(S_{i t+1}=k \mid S_{i t}=j, X_{i t+1}=x_{i t+1}\right)}{p\left(S_{i t+1}=j \mid S_{i t}=j, X_{i t+1}=x_{i t+1}\right)}=\beta_{0 j k}+x_{i t+1} \beta_{1 j k}, j \neq k, t \geq 1
\end{gathered}
$$

Specifically, $X_{i t}$ and $S_{i t}$ in the formulas are determinants that influence the state transition of an RIC. $\beta_{0 k}, \beta_{1 k}, \beta_{0 j k}$, and $\beta_{1 j k}$ are parameters to be estimated and common across the panel. For a more parsimonious model, we can rely on the following parameterization for transition probabilities instead of using Equation (6), that is, a multinomial logit model based on the difference between two sets of parameters:

$$
\log \frac{p\left(S_{i t+1}=k \mid S_{i t}=j, X_{i t+1}=x_{i t+1}\right)}{p\left(S_{i t+1}=j \mid S_{i t}=j, X_{i t+1}=x_{i t+1}\right)}=\beta_{0 j k}+x_{i t+1}\left(\beta_{1 j}-\beta_{1 k}\right), j \neq k, t \geq 1
$$

To ensure model identifiability, we set $\beta_{11}=0$ [41], which means that we only analyzed scenarios of transition to other states except for the lowest one.

\subsubsection{Estimation and Identification}

In this study, the expectation-maximization algorithm was applied to estimate the parameters of the HMM and to identify the most suitable numbers of RIC states. For testing the significance level of parameters, the standard deviation of parameters was estimated by bootstrap, and the $p$-value was calculated. We estimated the HMM using R package LMest V2.6.1.

Since the number of RIC hidden states (the number of elements in the set of $S=\{1,2, \cdots, n\}$ ) could not be given in advance, it was important to determine the most suitable number of RIC hidden states in the HMM. For choosing between models with a different number of RIC hidden states, we needed to consider the number of parameters. To effectively identify the state number of RIC, this study selected AIC (Akaike information criterion) and BIC (Bayesian information criterion) as the selection criteria [48]. The formulas of AIC and BIC are: $A I C=2 k-2 \ln (L)$ and BIC $=\ln (n) k-2 \ln (L)$, where $\mathrm{k}$ is the number of parameters in the model, $\mathrm{L}$ is computed using Equation (3), and $n$ is the number of regions. Based on the estimation results of different models, the corresponding state number was the optimal state number of RIC when the two criteria of the model reached the minimum.

Given the optimal number of hidden states and observed sequences (corresponding to $O(i)$ ), inferences regarding the hidden states of RIC could be made, and then it was feasible to compute the posterior probabilities of states given the observed sequences of region $i$, which further gave the probability of being in each RIC hidden state at each time point. For tracking the RIC hidden state of a region over time, the most likely sequence of RIC states could be obtained through the process of global decoding based on an adaptation of the Viterbi algorithm [57].

\subsection{Variable and Data}

The variables adopted in this study comprised two types: measurement variables of RIC state and determinants affecting the RIC state transition. First, well-accepted measurement variables from both the input and output perspectives, such as R\&D capital, the number of high-tech employees, and patent quantity, were adopted to measure RIC, [49,50]. Second, the composition and milieus of a regional innovation system are the most important determinants of RIC from the perspective of building up an innovation system. Therefore, this study also conceptualized the determinants of RIC state transition in this way, i.e., incorporating the effects of innovation subjects (e.g., enterprises, universities, research institutes, and interactions among them) and innovation environments (e.g., gov- 
ernment intervention, industrial structure, and intellectual property protection) $[27,58]$. The details of measurement and determinant variables are as follows.

\subsubsection{Measurement Variables of RIC State}

(1) Regional innovation output indicator. This study selected the number of invention patents to measure innovation output since utility model patent and design patent are of little economic value and low technical qualities. In addition, this study only considered service invention patent quantity (INNO) as innovation output due to the fact that individual R\&D investment is not recorded in China's innovation investment resources statistics. Finally, this study assumed that a patent is granted with a lag of 3 years based on Li's practice [27].

(2) Regional innovation input indicators. The input elements of regional innovation are mainly measured by knowledge stock and R\&D investment. On one hand, the level of knowledge stock (KNOW) equals the average year of schooling multiplied by regional employment. Specifically, the average years of schooling were modeled as $E_{t}=\sum\left(P_{i t} \times e_{i}\right) / \sum P_{i t}$, where $P_{i t}$ is the number of workers at the educational level $i$ in period $t$ and $e_{i}$ is the years of schooling at the educational level $i$. The educational level was divided into illiteracy and semi-illiteracy, primary school, junior high school, senior high school, and college or above, and educational years at each level were set as $0,6,3,3$, and 4 , respectively.

On the other hand, this study applied labor input and capital stock to represent $R \& D$ investment. The full-time equivalent of $R \& D$ personnel was adopted to measure the influence of labor input (RLA). The capital stock (RAS) was calculated by the perpetual inventory method [59]. The formula of the perpetual inventory method is:

$$
K_{i t}=\left(1-\delta_{i}\right) K_{i(t-1)}+I_{i(t-\varepsilon)} / P_{i(t-\varepsilon)}
$$

where $K_{i t}$ and $K_{i(t-1)}$ represent the capital stock of the region $i$ in period $t$ and $t-1$, respectively. $\delta_{i}$ is the R\&D capital depreciation rate for the region $i . I_{i(t-\varepsilon)}$ is the R\&D expenditure for the region $i$ in period $t-\varepsilon . P_{i(t-\varepsilon)}$ is the price index of R\&D expenditure for the region $i$ in period $t-\varepsilon$. $\varepsilon$, reflecting the time required for capital formation, is the lag period. Following Su's practice in 2017, the lag period of seven provinces, namely Beijing, Jilin, Heilongjiang, Hainan, Yunnan, Gansu, and Qinghai, was set at one year and that of the other provinces was set at zero year. Assuming that R\&D capital stock and R\&D expenditure have the same average growth rate, the estimation formula of the beginning capital stock is $K_{2000}=I_{2000} / g_{k}+\delta_{i}$, where $I_{2000}$ is R\&D expenditure at constant prices in 2000 and $g_{k}$ is the annual average growth rate of R\&D expenditure at constant prices during the periods. As for the estimation of $g_{k}$, the formula is $g_{k}=e^{m}-1$, where $m$ is determined by the regression model $\ln I_{t}=b+m t+\varepsilon_{t}$.

\subsubsection{Determinants of the RIC State Transition}

(1) The structural composition of innovation subjects: enterprises, universities, and research institutes are directly involved in all aspects of a regional innovation process. They are carriers and producers of new knowledge and innovative output. Due to the great differences in their objectives, structures, and operational practices, associated innovation efficiency also varies remarkably. Therefore, it was deemed realistic that the share of different innovation subjects significantly affects an RIC. To capture the distinct role of enterprises in the innovation process, the variable ENTP was included. It was constructed as the ratio of enterprises in intramural expenditure on $R \& D$, and intramural expenditure on R\&D of enterprises, universities, and research institutes were recorded in the China Science and Technology Statistics Yearbook. This study did not attempt to distinguish the difference between universities and research institutes, as they play similar roles within the innovation process in China. Thus, the share 
of R\&D expenditure by universities and research institutes could be expressed as 1-ENTP.

(2) The interactions among enterprises, universities, and research institutes: the interaction among innovation subjects has a crucial impact on the improvement of an RIC [60]. This study used the proportion of enterprise funds in intramural expenditure on $R \& D$ of universities to indicate the connection between enterprises and universities (ENTU). Meanwhile, we adopted the proportion of enterprise funds in intramural expenditure on the R\&D of research institutions to indicate the connection between enterprises and research institutes (ENTS). In addition, the China Science and Technology Statistics Yearbook started releasing the data of the intramural expenditure of universities and research institutions in 2009. Before 2009, the China Science and Technology Statistics Yearbook released the fund-raising situation of science and technology activities in each region of China. Hence, we used the share of enterprises in the funds for scientific and technological activities to represent the interactions among enterprises, universities, and research institutes in 2000-2008.

(3) The interaction between local innovators and external innovators: technology diffusion is one of the important sources of knowledge learning and production. In particular, advanced technological knowledge of developed economies is an important technological source for developing economies. Local innovation subjects can access this advanced technological information and knowledge via different channels, including foreign direct investment, technology import, and international trade [61]. In this sense, the level of regional opening-up is one of the important external factors affecting an RIC. With the improvement of regional openness, innovation subjects have more opportunities to obtain advanced technology and knowledge, so RIC is improved. The trade specialization index was adopted to reflect this pattern. It was defined as TRA $=($ export - import $) /($ export + import $)$. The value ranged from -1 to 1.

(4) Government support: the government plays an important role in providing institutional guarantees and financial support. The institutional guarantee refers to the regulation and coordination for innovation activities, including laws and innovation incentive policies, while the government also offers financial support and research funding to innovation subjects. The proportion of government funds in intramural expenditure on R\&D, denoted by GOV, was employed as a measure of the strength of a government's support. The intramural expenditure on R\&D by the source in the China Science and Technology Statistics Yearbook has only been published since 2009. Before 2009, China's Science and Technology Statistics Yearbook published the fund-raising situation of science and technology activities in China's regions separately. Hence, we used the proportion of government in the funds for science and technology activities to represent government support in 2000-2008.

(5) Financial support was recorded as FIN: innovation activities are often accompanied by substantial investment and risk. The financial sector can not only provide innovative capital for innovation subjects but also help them disperse certain risks. This study constructed FIN by dividing the amount of science and technology loans of financial institutions by the total science and technology funds raised in a region. Since 2008, China's Science and Technology Statistics Yearbook has no longer reported data on financial institutions' loans. This study used the intramural expenditure on R\&D minus the government, enterprises, and foreign funds to measure the technical loan of financial institutions.

(6) The technology market environment: the operation of technology market makes the transfer of knowledge assets and technology easier among various subjects, which is conducive to the diffusion and learning of knowledge. At the same time, a fine technology market environment also stimulates more innovation activities [60]. In this study, the technology market supply-demand environment is represented by the 
logarithm of the average technology market turnover of scientific and technological personnel, denoted by TEC.

(7) Characteristics of industrial structure: the microeconomic environment in which the innovation subject operates affects the efficiency and outcome of innovation activities [11]. In the study, the proportions of secondary and tertiary industries were used to reflect the impact of regional industrial structure on RIC, which were recorded as SECP and THRP, respectively.

(8) Regional human capital reserve: human capital is the basis of a knowledge economy. On the one hand, regions with a high-level human capital reserve can attract more innovative enterprises. On the other hand, human capital can also promote regional knowledge diffusion and production, as well as improve regional innovation capacity [56]. The regional human capital level in this study refers to the number of college students per 10,000 students, which was recorded as HUMR.

(9) Intellectual property protection: intellectual property protection mainly refers to patent protection. According to the Patent Law of the People's Republic of China, two modes are applied to protect intellectual property, namely administrative protection (ADMI) and judicial protection (LAWI). ADMI can be measured by the acceptance of patent infringement cases. This study calculated the patent infringement rate by dividing the accepted number of patent infringement cases by effective patent quantity. LAWI can be defined as the number of lawyers per 10,000 people [62]. The proportion of lawyers in the total population is a significant indicator of the level of judicial protection in a country or region. When the number of lawyers reaches 5 per 10,000 people, the level of judicial protection in the country or region has arrived at a higher level. Intellectual property disputes are often resolved through judicial litigation. The regional judicial level directly affects the intensity of intellectual property judicial protection.

\subsubsection{Data}

Concerning accessibility and completeness, the data used in this study covered 30 provincial administrative units in China over the period of 2000-2017. Tibet was excluded from the analysis due to a large proportion of missing data. Hong Kong, Macao, and Taiwan were also excluded due to the issue of statistic inconsistency. The original data were collected from the China Science and Technology Statistics Yearbook, the China Statistics Yearbook, the China Intellectual Property Rights Yearbook, the China Labor Statistics Yearbook, the State Intellectual Property Office's Annual Patent Review, and the Statistical Yearbook of the provinces. Table 1 lists the model variables. The summary statistics for the variables included in the HMM are shown in Table 2. Due to the lagging nature of innovation output, the statistical period of patents was from 2003 to 2017 and the statistical period of other variables was from 2000 to 2014. Generally, the RIC greatly fluctuates in terms of both innovation output and innovation input in China. For example, the average number of service invention patent (INNO) varies from 44,611 to 7 and the standard deviation is 6540.8. This might be due to China's rapid growth in innovation since 2000 and the large regional disparity in RIC. Additionally, by comparing the mean values of ENTU and ENTS, it could be concluded that the interactive effect between universities and enterprises is higher than that of between research institutes and enterprises. 
Table 1. Model variables. HMM: hidden Markov model.

\begin{tabular}{|c|c|c|}
\hline Label & Variable & Description \\
\hline \multicolumn{3}{|c|}{ Measurement variables of RIC state : corresponding to $O_{i t}$ in the HMM } \\
\hline INNO & Innovation output & Service invention patent quantity \\
\hline RAS & Capital stock & Capital stock calculated by the perpetual inventory method \\
\hline RLA & Innovation labor input & The full-time equivalent of R\&D personnel \\
\hline KNOW & Knowledge stock & The average year of schooling multiplied by the regional employment \\
\hline \multicolumn{3}{|c|}{ Determinants of the RIC state transition : corresponding to $X_{i t}$ in the HMM } \\
\hline ENTP & $\begin{array}{l}\text { The structural composition of } \\
\text { innovation subjects }\end{array}$ & The ratio of enterprises in intramural expenditure on $R \& D$ \\
\hline ENTS & $\begin{array}{l}\text { The connection between enterprises } \\
\text { and research institutes }\end{array}$ & $\begin{array}{l}\text { The proportion of enterprise funds in intramural expenditure on R\&D of } \\
\text { research institutions }\end{array}$ \\
\hline ENTU & $\begin{array}{l}\text { The connection between enterprises } \\
\text { and universities }\end{array}$ & $\begin{array}{l}\text { The proportion of enterprise funds in intramural expenditure on R\&D of } \\
\text { universities }\end{array}$ \\
\hline TRA & $\begin{array}{l}\text { The interaction between local } \\
\text { innovators and external innovators }\end{array}$ & Trade specialization index \\
\hline GOV & Government support & The proportion of government funds in intramural expenditure on $R \& D$ \\
\hline FIN & Financial support & $\begin{array}{l}\text { Dividing the amount of science and technology loans of financial institutions by } \\
\text { the total science and technology funds }\end{array}$ \\
\hline TEC & Technology market environment & $\begin{array}{l}\text { The logarithm of the average technology market turnover of scientific and } \\
\text { technological personnel }\end{array}$ \\
\hline SECP & Characteristics of industrial structure & The proportion of secondary industry \\
\hline THRP & Characteristics of industrial structure & The proportion of tertiary industry \\
\hline HUMR & Regional human capital reserve & The number of college students per 10,000 students \\
\hline ADMI & $\begin{array}{l}\text { The intensity of intellectual property } \\
\text { administrative protection }\end{array}$ & The acceptance of patent infringement cases \\
\hline LAWI & $\begin{array}{l}\text { The intensity of intellectual property } \\
\text { judicial protection }\end{array}$ & The number of lawyers per 10,000 people \\
\hline
\end{tabular}

Table 2. Descriptive statistics of model variables.

\begin{tabular}{|c|c|c|c|c|c|}
\hline Label & Variable & Mean & S. D. & Max & Min \\
\hline \multicolumn{6}{|c|}{ Measurement variables of RIC state : corresponding to $O_{i t}$ in the HMM } \\
\hline INNO & Innovation output & 3280.2 & 6540.8 & 44,611 & 7 \\
\hline RAS & Capital stock & 406.8 & 646.1 & 4113.4 & 1.9 \\
\hline RLA & Innovation labor input & $66,413.3$ & $80,302.2$ & $506,861.8$ & 848 \\
\hline KNOW & Knowledge stock & 39.7 & 28.2 & 188.4 & 2.8 \\
\hline \multicolumn{6}{|c|}{ Determinants of the RIC state transition : corresponding to $X_{i t}$ in the HMM } \\
\hline ENTP & The structural composition of innovation subjects & 0.67 & 0.19 & 0.94 & 0.13 \\
\hline ENTS & Connection between enterprises and research institutes & 0.04 & 0.04 & 0.3 & 0 \\
\hline ENTU & Connection between enterprises and universities & 0.29 & 0.14 & 0.63 & 0 \\
\hline TRA & The interaction between local innovators and external innovators & 0.12 & 0.27 & 0.74 & -0.71 \\
\hline GOV & Government support & 0.25 & 0.12 & 0.62 & 0.07 \\
\hline FIN & Financial support & 0.05 & 0.03 & 0.23 & 0 \\
\hline TEC & Technology market environment & 2.42 & 2.71 & 4.85 & -2.76 \\
\hline SECP & Characteristics of industrial structure & 0.46 & 0.08 & 0.59 & 0.2 \\
\hline THRP & Characteristics of industrial structure & 0.41 & 0.08 & 0.78 & 0.28 \\
\hline HUMR & Regional human capital reserve & 138 & 72 & 356.5 & 21.2 \\
\hline ADMI & Intensity of intellectual property administrative protection & 0.99 & 0.02 & 1 & 0.84 \\
\hline LAWI & Intensity of intellectual property judicial protection & 1.53 & 1.64 & 11.69 & 0.34 \\
\hline
\end{tabular}




\section{Research Results}

Using the expectation-maximization algorithm, the unified estimation of the HMM produced the following results: the dynamics of RIC state transition and the heterogeneity of determinants across states. Grounded on the underlying methodological assumptions, the HMM estimated the dynamics of RIC state transition by identifying the suitable number of RIC transition states and the probability of each transition. Finally, based on the results estimated by the first two steps, a multinomial logit approach estimated the heterogeneity of determinants in different states.

\subsection{Panel Unit Root Test}

A stationarity test was initially performed to check the stationary properties of variables. To ensure the robustness of our test results, the R package "plm" was adopted to perform the inverse chi-square test, the inverse normal test, and the logit test [63] in order to verify whether each variable had a unit root with both individual intercept and time trend (I\&T) or only individual intercept (I). All these tests were based on the estimation of augmented Dickey-Fuller (ADF) regressions for each time series. The null hypothesis of the unit root test was that "the time series are unit-root nonstationary." Accordingly, the results of the panel unit root test are listed in Table 3, which reveals that the variables in the model were stationary and satisfied the HMM conditions by rejecting the existence of the unit root hypothesis.

Table 3. Panel unit root test of variables. I\&T: intercept and time trend.

\begin{tabular}{|c|c|c|c|c|c|c|}
\hline \multirow{2}{*}{ Variable } & \multicolumn{2}{|c|}{ Inverse Chi-Square Test } & \multicolumn{2}{|c|}{ Inverse Normal Test } & \multicolumn{2}{|c|}{ Logit Test } \\
\hline & I\&T & I & I\&T & $\mathbf{I}$ & I\&T & I \\
\hline INNO & $275.98^{* * *}$ & $90.45^{* * *}$ & $-9.3198^{* * *}$ & $-8.8781^{* * *}$ & $-12.364^{* * *}$ & $-23.084^{* * *}$ \\
\hline RAS & $360.84^{* * *}$ & $166.45^{* * *}$ & $-1.6816^{*}$ & $-2.2943^{* *}$ & $-3.2709 * * *$ & $-3.3183^{* * *}$ \\
\hline RLA & $267.12^{* * *}$ & $139.21^{* * *}$ & $-4.5454^{* * *}$ & $-2.11^{* *}$ & $-9.6731^{* * *}$ & $-8.0372^{* * *}$ \\
\hline KNOW & $149.15^{* * *}$ & $147.62^{* * *}$ & $-3.5744^{* * *}$ & $-1.9447 *$ & $-3.6669 * * *$ & $-2.198^{* *}$ \\
\hline ENTP & $300.78^{* * *}$ & $273.54^{* * *}$ & $-7.6047^{* * *}$ & $-7.0787^{* * *}$ & $-12.731^{* * *}$ & $-11.363^{* * *}$ \\
\hline ENTS & $316.99^{* * *}$ & $448.6^{* * *}$ & $-10.675^{* * *}$ & $-13.911^{* * *}$ & $-14.75^{* * *}$ & $-22.361^{* * * *}$ \\
\hline ENTU & $225.9^{* * *}$ & $148.17^{* * *}$ & $-5.5718^{* * *}$ & $-4.84^{* * *}$ & $-8.1705^{* * *}$ & $-5.7025^{* * *}$ \\
\hline TRA & $370.07^{* * *}$ & $159.91^{* * *}$ & $-10.88^{* * *}$ & $-3.3734^{* *}$ & $-16.747^{* * *}$ & $-5.2095^{* * *}$ \\
\hline GOV & $287.09^{* * *}$ & $138.57^{* * *}$ & $-9.4387^{* * *}$ & $-3.2454^{* * *}$ & $-12.926^{* * *}$ & $-4.097^{* * *}$ \\
\hline FIN & $317.94^{* * *}$ & $262.36^{* * *}$ & $-9.2492^{* * *}$ & $-8.6846^{* * *}$ & $-14.09 * * *$ & $-12.027^{* * *}$ \\
\hline TEC & $352.74^{* * *}$ & $196.34^{* * *}$ & $-4.8296^{* * *}$ & -0.46363 & $-14.015^{* * *}$ & $-3.5891^{* * *}$ \\
\hline SECP & $142.46^{* * *}$ & $126.21^{* * *}$ & $-1.9487^{*}$ & $-3.461^{* *}$ & $-4.7048^{* * *}$ & $-4.5685^{* * *}$ \\
\hline THRP & $173.83^{* * *}$ & $93.651^{* * *}$ & $-3.3935^{* * *}$ & $-4.378^{* *}$ & $-14.975^{* * *}$ & $-13.29^{* * *}$ \\
\hline HUMR & $389.08^{* * *}$ & $476.86^{* * *}$ & $-3.7295^{* * *}$ & $-13.413^{* * *}$ & $-14.452^{* * *}$ & $-22.785^{* * *}$ \\
\hline ADMI & $676.04^{* * *}$ & $456.84^{* * *}$ & $-12.831^{* * *}$ & $-12.559^{* * *}$ & $-30.834^{* * *}$ & $-22.354^{* * *}$ \\
\hline LAWI & $139.24^{* * *}$ & 5.1049 & $-13.1743^{* * *}$ & -2.825 & $-10.48187^{* * *}$ & $-3.37^{* * *}$ \\
\hline
\end{tabular}

\subsection{Selection of the Number of RIC States}

Table 4 shows the estimation results of two criteria under the different numbers of states using the above data. Among the one, two, three, and four state models, the model with three states had the smallest AIC and BIC, suggesting that China's RIC should include three states, i.e., high $(\mathrm{H})$, medium $(\mathrm{M})$, and low $(\mathrm{L})$, the corresponding values of which would be 3,2, and 1, respectively. The three states of RIC indicated that china's RIC roughly experienced three stages of development in terms of the innovation investment and outcome during the observation period. 
Table 4. Number selection of RIC state. AIC: Akaike information criterion; BIC: Bayesian information criterion.

\begin{tabular}{ccccc}
\hline Number of States & Log-Likelihood & AIC & BIC & Number of Parameters \\
\hline 1 & -1386.79 & 2801.58 & 2821.20 & 15 \\
2 & -1149.05 & 2412.10 & 2491.97 & 57 \\
3 & -997.74 & 2147.48 & $\mathbf{2 4 2 4 . 0 3}$ & $\mathbf{1 2 6}$ \\
4 & -889.77 & 2221.55 & 2531.21 & 221 \\
\hline
\end{tabular}

\subsection{State Transition of RIC}

This study initially estimated the RIC states of 30 regions. As shown in Figure 2, the variable on the horizontal axis is the year, and the variable on the vertical axis is the annual average state of RIC in all regions. The curve in the figure shows the trend of the domestic average state of RIC over time. China's RIC presented an upward trend from 2000 to 2014. The average number presenting RIC state was 1.7 from 2000 to 2002. Since 2002, the average state of RIC in China has been experiencing rapid growth. The average number presenting RIC state reached 2.6 by 2014.

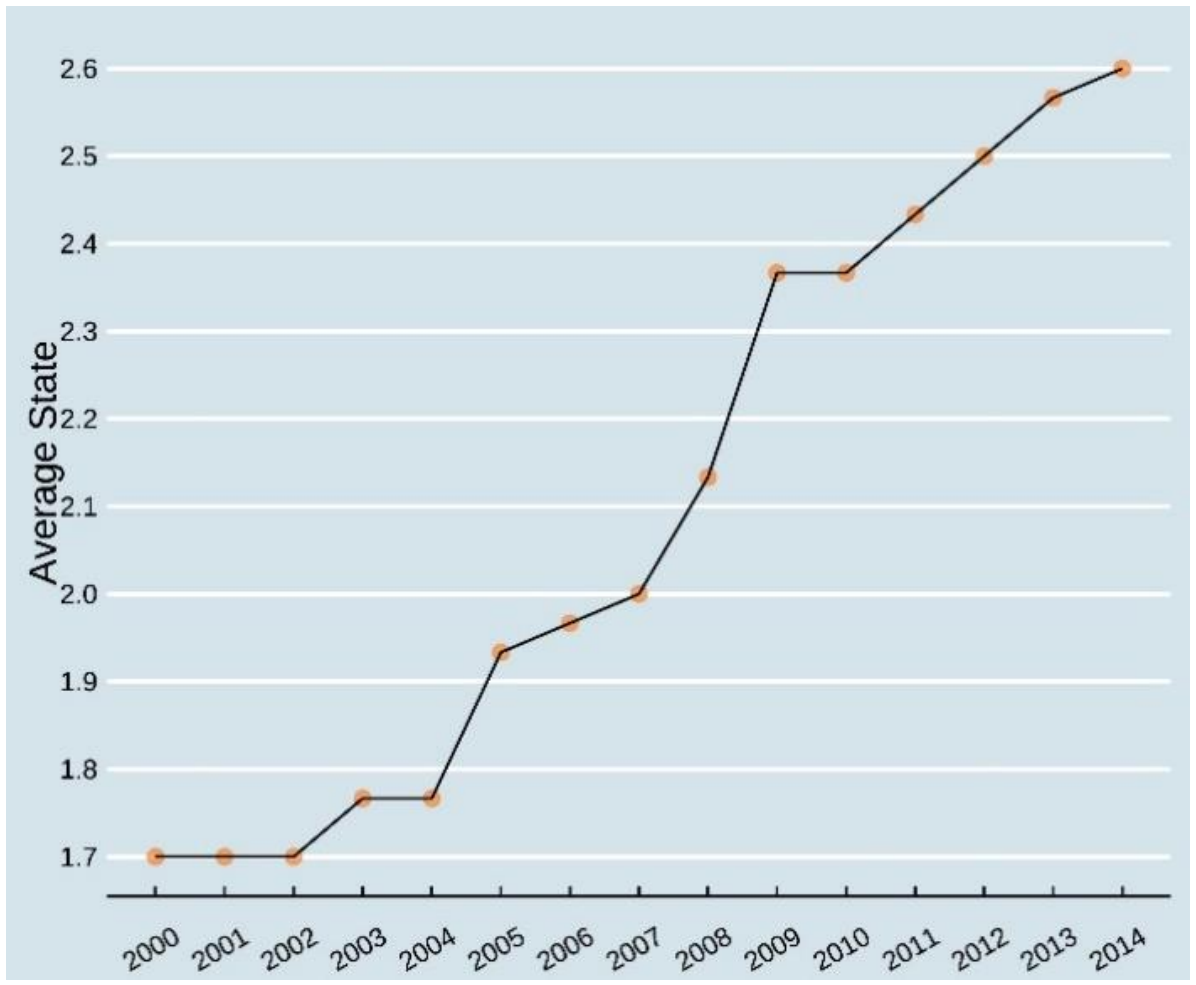

Figure 2. The average state of RIC in all regions between 2000 and 2014.

Figure 3 shows the distribution of the RIC states during the observation period, where the two curves plot the boundaries that separate the low, medium, and high states. In Figure 3, the variable on the horizontal axis are years and the variable on the vertical axis are percentage. The lower curve in the figure shows the proportion of regions with low innovation capacity in all regions each year. The higher curve shows the proportion of regions with low and medium innovation capacity in all regions each year. The area between the two curves represents the proportion of regions with medium innovation capacity, and the upper part of the higher curve is the proportion of regions with high innovation capacity. Over the period of 2000-2003, 40 percent of all regions are in the low state of innovation capacity, and only 10 percent of the regions are in the high state. The share of regions with a low innovation capacity began to decrease rapidly since 2003, while the share of regions with a high innovation capacity significantly increased, and the share 
of regions with a medium innovation capacity remained unchanged. However, such a decreasing trend started to become steady, with an annual average rate of 10 percent in 2009 and onwards, and the regions with a medium state entered into a quick stage to the high state over the period of 2010-2014. By 2014, 20 percent of regions were in the medium state of innovation capacity, and 70 percent of regions are in the high state of innovation capacity.

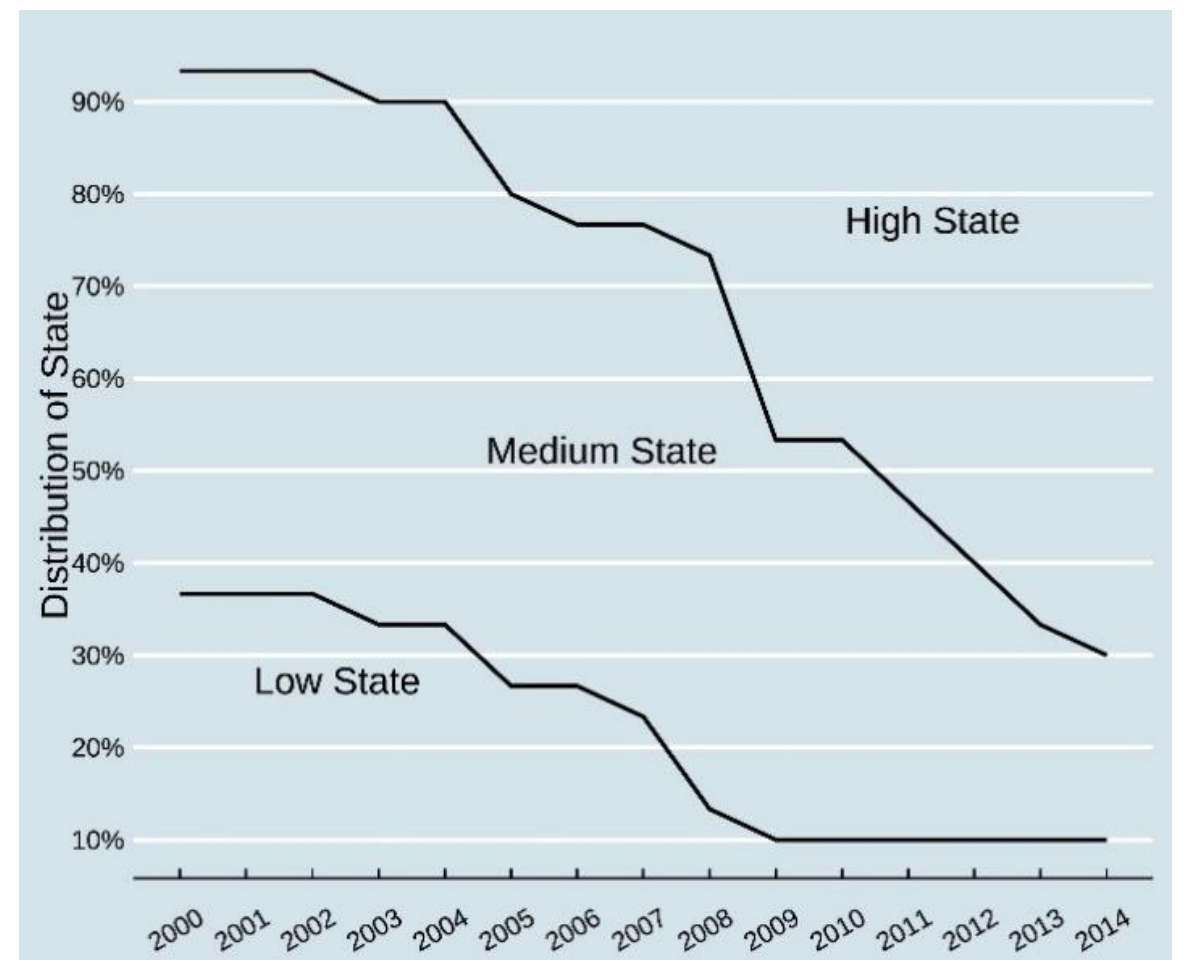

Figure 3. Distribution of RIC between 2000 and 2014.

Figure 4 represents a scatter plot of the transition of RIC from 2000 to 2014. During this period, the RIC states in different regions experienced different transition processes. (1) The RIC state of three regions, namely Jiangxi, Inner Mongolia, and Chongqing, experienced all the high, medium, and low states of RIC. (2) The RIC state of sixteen regions experienced the medium and high states; these sixteen regions were Anhui, Fujian, Hebei, Henan, Heilongjiang, Hubei, Hunan, Jiangsu, Liaoning, Shandong, Shanxi, Shaanxi, Shanghai, Sichuan, Tianjin, and Zhejiang. The average duration of stay for the RIC of these sixteen regions in the medium state was 8.44 years. The RIC of Shanghai reached a high state from a medium state within only two years, while Heilongjiang and Shanxi took the longest transition period, i.e., 13 years, to change their RIC from a medium state to a high state over the period of 2000-2012. The RIC state of five regions, namely Gansu, Guangxi, Guizhou, Xinjiang, and Yunnan, experienced a low state and a medium state during the period of observation. The RIC state of these five regions changed from a low state to a medium state around 2007, and it then stayed in the medium state until 2014. (3) The RIC state of six regions only remained in one state over the period of 2000-2014. Specifically, Beijing and Guangdong were always in a high state of RIC in the observation period. The RIC state of Jilin was in the medium state, while the RIC states of Hainan, Ningxia, and Qinghai were always low. 


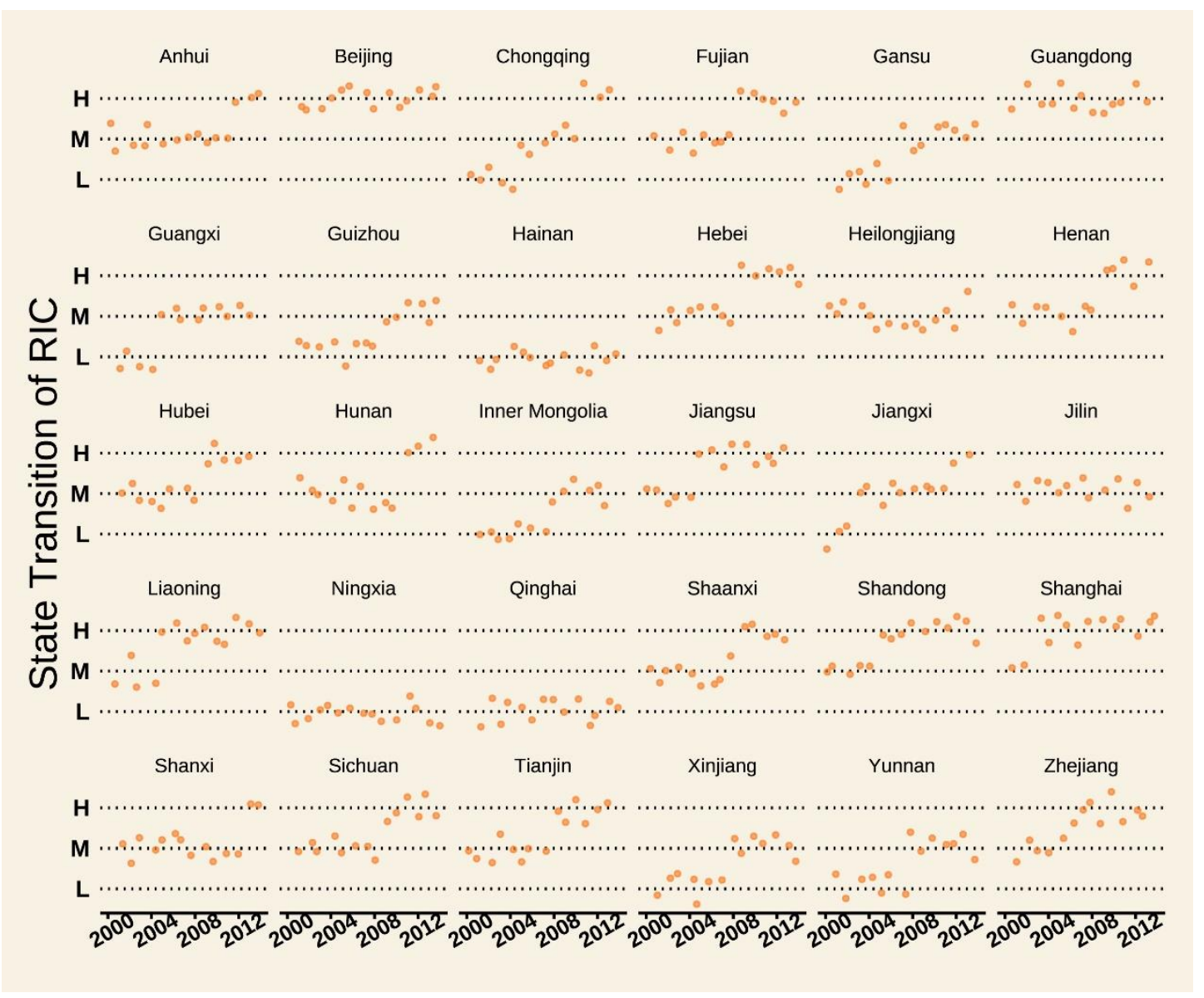

Figure 4. RIC transition between 2000 and 2014.

\subsection{Transition Probability of RIC State}

The average transition probabilities of RIC states exhibit nine scenarios, as shown in Table 5. For example, when the state of RIC is low in period $t$, the probability that RIC state remains in the low state in period $t+1$ is $43.05 \%$. The probability of RIC developing from a low state to a medium state is higher than that of innovation capacity from a medium state to a high state, which indicates that the growth rate of RIC is gradually decreasing [25].

Table 5. Average transition probability of RIC state.

\begin{tabular}{cccc}
\hline $\boldsymbol{t} \rightarrow \boldsymbol{t}+\mathbf{1}$ & Low State & Medium State & High State \\
\hline Low state & $43.05 \%$ & $56.95 \%$ & $0 \%$ \\
Medium state & $0 \%$ & $76.36 \%$ & $23.64 \%$ \\
High state & $0 \%$ & $26.06 \%$ & $73.94 \%$ \\
\hline
\end{tabular}

\subsection{Estimated Results of the Determinants Affecting RIC State Transitions}

Table 6 reports the estimated parameters of the three-state HMM. To analyze the heterogeneous impacts of innovation subjects and innovation environments on RIC transitions, three states were used as reference groups for estimation.

Using the low-state group as the reference group, this study estimated the determinants of RIC state transitions and presents the results in columns 2 and 3 of Table 4. Two determinants as the innovation subjects were found to exert significant and positive impacts on the probability of RIC state transition from a low state to a medium state, namely ENTU and TRA. However, the effects of ENTU and TRA were not significant in the case of an RIC's transition from a low state to a high state. Four determinants as innovation 
environment factors were all found to exert significant impacts on the probability of the RIC transition from a low state to a higher state, ADMI, SECP, THRP, and HUMR.

Table 6. Results of RIC state transition.

\begin{tabular}{|c|c|c|c|c|c|c|}
\hline \multirow{2}{*}{ Variables } & \multicolumn{2}{|c|}{ Reference Group = Low State } & \multicolumn{2}{|c|}{ Reference Group = Medium State } & \multicolumn{2}{|c|}{ Reference Group $=$ High State } \\
\hline & Medium State & High State & Medium State & High State & Medium State & High State \\
\hline ENTP & $\begin{array}{l}14.88 \\
(8.68)\end{array}$ & $\begin{array}{l}11.21 \\
(9.30)\end{array}$ & $\begin{array}{c}-13.05^{*} \\
(7.58)\end{array}$ & $\begin{array}{c}21.13^{* * *} \\
(7.98)\end{array}$ & $\begin{array}{l}-7.39 \\
(5.86)\end{array}$ & $\begin{array}{c}-76.95^{* * *} \\
(27.88)\end{array}$ \\
\hline ENTS & $\begin{array}{c}9.15 \\
(13.88)\end{array}$ & $\begin{array}{c}18.40 \\
(11.35)\end{array}$ & $\begin{array}{l}-3.05 \\
(3.70)\end{array}$ & $\begin{array}{c}14.12 \\
(10.53)\end{array}$ & $\begin{array}{l}-4.33 \\
(3.89)\end{array}$ & $\begin{array}{l}-38.97 \\
(26.12)\end{array}$ \\
\hline ENTU & $\begin{array}{c}22.32 * * * \\
(5.53)\end{array}$ & $\begin{array}{c}6.62 \\
(11.42)\end{array}$ & $\begin{array}{l}-4.61 \\
(7.89)\end{array}$ & $\begin{array}{c}11.85^{* * *} \\
(3.88)\end{array}$ & $\begin{array}{c}-8.58 \\
(17.06) \\
\end{array}$ & $\begin{array}{c}-137.07^{* * * *} \\
(39.11)\end{array}$ \\
\hline TRA & $\begin{array}{c}10.56^{* * *} \\
(2.81)\end{array}$ & $\begin{array}{c}5.31 \\
(8.05)\end{array}$ & $\begin{array}{c}3.41 \\
(6.80)\end{array}$ & $\begin{array}{c}-6.69 * * \\
(3.37)\end{array}$ & $\begin{array}{c}3.05 \\
(6.91)\end{array}$ & $\begin{array}{c}19.56 \\
(15.00)\end{array}$ \\
\hline GOV & $\begin{array}{c}4.20 \\
(9.53)\end{array}$ & $\begin{array}{c}8.54 \\
(11.42)\end{array}$ & $\begin{array}{c}1.79 \\
(8.11)\end{array}$ & $\begin{array}{c}7.20 \\
(10.51)\end{array}$ & $\begin{array}{c}3.25 \\
(7.12)\end{array}$ & $\begin{array}{c}36.61 \\
(34.24)\end{array}$ \\
\hline FIN & $\begin{array}{c}-8.47 \\
(19.50)\end{array}$ & $\begin{array}{l}-2.13 \\
(6.96)\end{array}$ & $\begin{array}{c}1.95 \\
(2.43)\end{array}$ & $\begin{array}{l}-2.09 \\
(9.01)\end{array}$ & $\begin{array}{c}0.74 \\
(2.07)\end{array}$ & $\begin{array}{c}6.82 \\
(20.49)\end{array}$ \\
\hline TEC & $\begin{array}{l}-0.14 \\
(0.12)\end{array}$ & $\begin{array}{l}-0.16 \\
(0.42)\end{array}$ & $\begin{array}{l}-0.17 \\
(0.42)\end{array}$ & $\begin{array}{l}-0.03 \\
(0.09)\end{array}$ & $\begin{array}{c}0.21 \\
(0.37) \\
\end{array}$ & $\begin{array}{l}-0.41 \\
(0.38)\end{array}$ \\
\hline SECP & $\begin{array}{c}11.53^{* *} \\
(4.57)\end{array}$ & $\begin{array}{c}10.95^{* *} \\
(4.51)\end{array}$ & $\begin{array}{c}-9.97^{* *} \\
(3.93)\end{array}$ & $\begin{array}{c}10.63^{* *} \\
(5.12)\end{array}$ & $\begin{array}{c}-7.34^{* *} \\
(3.56)\end{array}$ & $\begin{array}{c}-15.12^{* * *} \\
(4.12)\end{array}$ \\
\hline THRP & $\begin{array}{c}-45.61 * * \\
(16.65)\end{array}$ & $\begin{array}{c}-14.25^{* *} \\
(6.93)\end{array}$ & $\begin{array}{l}8.31 * \\
(4.33)\end{array}$ & $\begin{array}{c}-21.42^{* * *} \\
(7.92)\end{array}$ & $\begin{array}{l}8.22 * \\
(4.58)\end{array}$ & $\begin{array}{c}18.51^{* * *} \\
(5.71)\end{array}$ \\
\hline HUMR & $\begin{array}{c}0.17^{* * *} \\
(0.04)\end{array}$ & $\begin{array}{c}0.14 \\
(0.10) \\
\end{array}$ & $\begin{array}{c}-0.16^{*} \\
(0.09)\end{array}$ & $\begin{array}{l}0.05^{* *} \\
(0.03)\end{array}$ & $\begin{array}{c}-0.19 * * \\
(0.09)\end{array}$ & $\begin{array}{c}-0.25 \text { * } \\
(0.13)\end{array}$ \\
\hline ADMI & $\begin{array}{c}2.24^{* * *} \\
(0.34)\end{array}$ & $\begin{array}{c}13.06^{* *} \\
(5.90)\end{array}$ & $\begin{array}{c}5.65 \\
(4.32)\end{array}$ & $\begin{array}{c}14.71 * * * \\
(3.70)\end{array}$ & $\begin{array}{c}1.49 \\
(3.65)\end{array}$ & $\begin{array}{c}60.64^{* * *} \\
(16.30)\end{array}$ \\
\hline LAWI & $\begin{array}{c}1.47 \\
(2.85)\end{array}$ & $\begin{array}{c}2.13 \\
(5.91)\end{array}$ & $\begin{array}{l}-6.43 \\
(5.10)\end{array}$ & $\begin{array}{l}3.80 * * \\
(1.59)\end{array}$ & $\begin{array}{l}-2.97 \\
(2.85)\end{array}$ & $\begin{array}{l}-1.45 \\
(4.00)\end{array}$ \\
\hline
\end{tabular}

Note: ${ }^{* * *} p<0.01 ;{ }^{* *} p<0.05 ;{ }^{*} p<0.1$. The value in parentheses is the standard deviation.

Using the medium state group as the reference group, this study further estimated the determinants of RIC state transitions and presents the results in columns 4 and 5 of Table 4 . Three determinants as the innovation subjects were found to exert significant impacts on the probability of the RIC transition from a medium state to a high state or remaining in a medium state, namely ENTP, ENTU, and TRA. Five determinants as innovation environment factors were found to exert significant impacts on the probability of an RIC transition from a medium state to a high state or remaining in a medium state, namely ADMI, LAWI, SECP, THRP, and HUMR.

Using the high-state group as the reference group, this study estimated the determinants of RIC state transitions and presents the results in columns 6 and 7 of Table 4. Two determinants as the innovation subjects were found to exert significant impacts on the probability of an RIC transition remaining in a high state, namely ENTP and ENTU. Four determinants, as the proxies for representing the quality of innovation environment, were found to exert significant impacts on the probability of an RIC transition from a high state to a medium state or remaining in a high state, namely SECP, THRP, ADMI, and HUMR.

\section{Discussion}

\subsection{RIC State Transition}

At this regional level, this study provides a specific standard to define the stage of innovation capacity development and how such a capacity evolves across different regions 
and over time. The results showed that China's RIC has experienced three states (i.e., low, medium, and high) that portrayed a similar pattern to that found by Lei et al. [39], who argued that the development trajectory of China's technological innovation follows a process of "introducing-imitating-improving," "integrating-boosting-creating," and "innovating-iterating-promoting." However, this study further revealed the internal mechanism of a regional innovation system. Based on preliminary results, it appears that the development of an RIC shows the features of certain path-dependence and lock-in effect. It is difficult to change the state of an RIC when it continuously stays in a certain state. The lock-in effect is most significant in the case of the medium state, followed by the high state. This might due to the fact that regions with a low RIC have the advantages of being late-movers [14]. Regions in the low state of RIC can carry out technological innovations by building on technological import and technological imitation. In comparison, regions with a superior level of technological innovation can hardly benefit from late-mover advantages, as they can only conduct independent innovation, which, in turn, slows down the overall growth of the RIC.

\subsection{Heterogeneous Determinants of RIC State Transition}

\section{(1) Determinants of RIC State Transitions in the Low State}

ENTU and TRA were found to exert significant and positive impacts on the probability of an RIC state transition from a low state to a medium state. However, the effects of ENTU and TRA were not found to be significant in the case of an RIC transition from a low state to a high state. Prior studies indicated that ENTU and TRA were two critical determinants that result in RIC disparities across different regions or countries [27,49]. This study confirmed this claim and further expanded the investigation towards the process of RIC transition. The results suggested that the interaction among innovation subjects could also effectively facilitate knowledge flow and aid an RIC transition to a higher state.

ADMI was found to have positive and significant impacts in the case of an RIC transition from a low state to medium and high states, whereas this was not the case for LAWI. These results suggested that innovation protection has a positive effect on the improvement of China's RIC, and administrative protection exerts a stronger impact on the development of RIC than that of judicial protection in the case of a low RIC. The development of the secondary industry can improve an RIC in a low state. However, the development of tertiary industries was found to have an adverse effect on the development of RIC in the case of a low state. This might be due to the fact that a tertiary industry mainly provides labor-intensive services in regions with a low-state RIC [64]. Hence, the technological innovation of the tertiary industry is insufficient, and the outcome of technological innovation has little added value. In addition, the coefficient of secondary industry is opposite to that of the tertiary industry in all cases. This can be deemed realistic, as there is a competition in capital and labor between tertiary and secondary sectors in these regions with a low RIC; capital and labor may flow to tertiary industries from secondary industries. HUMR was found to have significant and positive impacts on an RIC transition from a low state to a medium state, but such an effect was found to be insignificant in the case of an RIC transition from a low state to a high state, implying that it cannot facilitate an RIC's achievement of the leap.

\section{(2) Determinants of RIC State Transitions in the Medium State}

ENTP and ENTU were found to have positive and significant impacts in the case of an RIC transition from a medium state to a high state. The results suggested that enterprises are the critical driving force of RIC improvement in regions with a medium RIC. Additionally, the cooperation between enterprises and universities is conducive to the flow and accumulation of knowledge, thus facilitating the development of RIC. TRA was found to have significant and negative effects in the case of an RIC transition from a medium state to a high state. Based on the formula of trade specialization index, the results suggested that the probability of an RIC transition from a medium state to a high 
state decreases with an increase of regional net exports. This may be due to the fact that China's export industries are mainly labor-intensive. These export industries are in the low end of the global value chain, and they mainly engage in the secondary processing and assembling of products. Without proficient ability, these export industries are less able to lead technological innovation. Additionally, the development of low-value-added export industries crowds out the resources of innovative industries and reduces the RIC in these regions. ENTP was found to have negative and significant impacts in the case of an RIC remaining in a medium state. This result suggested that the enterprise-dominated mode of regional innovation can prevent the occurrence of lock-in effect in regions with a medium RIC.

ADMI and LAWI were found to have significant and positive impacts on an RIC transition from a medium state to a high state. The results further validated the critical role of intellectual property protection to motivate technological innovation [65]. By comparing to the situation of RIC in a low state, we found that judicial protection has a positive and stronger effect on RIC development in a medium state. Intuition suggests that innovation in regions with a low RIC is mainly generated through the process of technology diffusion, such as technology imitation. However, judicial protection is mainly negatively associated with such technology diffusion [66]. Therefore, it is plausible that intellectual property judicial protection is less likely to facilitate the development of innovation capacity in regions with a low RIC. SECP and HUMR were found to have significantly positive impacts on RIC development in the case of an RIC transition from a medium state to a high state, while THRP as found to have significantly negative impacts. SECP, HUMR, and THRP were found to exert similar effects on RIC development when an RIC transitions from a medium state to a high state and from a low state to a medium state. HUMR and SECP were found to have significantly negative impacts on RIC development in the case of an RIC remaining in a medium state, while THRP was found to have a significantly positive impact. These results implied that the development of secondary industries contributes to the development of RIC. However, the development of tertiary industries increases the lock-in effect when RIC is in a medium state. This may be due to the fact that tertiary industries in most regions of China are dominated by low value-added consumer services and lack of further innovation. In other words, the proportion of productive services in the tertiary industry is relatively low when the tertiary industry is dominated by low value-added consumer services. Due to the insufficient development of productive services, it is difficult for a region to effectively improve production and innovation the efficiency of the secondary industry.

\section{(3) Determinants of RIC State Transitions in the High State}

ENTU and ENTP were found to have significantly negative impacts in the case of an RIC transition remaining in a high state. The results suggested that the enterprise-dominant mode of regional innovation can help a region to remain in a high state of RIC. Motivated by policy incentives and the competition of commercial intellectual property enterprises are more inclined to apply for patents. The reason is twofold; first, China provides policy incentives and supports, such as tax policies, to high-tech enterprises identified by a local government, which often uses the number of patents owned by an enterprise as a critical index to measure its high-tech nature. Thus, enterprises are keen to apply for more patents in facilitating the process of high-tech identification. Second, a commercial intellectual property guarantees the sustainable profits of enterprises compared to universities and research institutes that are more inclined to focus on research. Therefore, the enterprisedominant mode possesses a large number of patents and contributes to an RIC remaining in a high state [27].

HUMR and SECP were found to have significantly negative impacts on RIC in the case of an RIC transition from a high state to a medium state, while was found to have significantly positive impacts. The results revealed that the development of secondary industries and the accumulation of human capital can effectively prevent the decline of RIC. However, the development of tertiary industries was found to lead to a decrease 
in RIC. One possible reason is that China's present tertiary industry is labor-intensive, low value-added, and lacks of innovation [64]. ADMI and THRP were found to have significantly positive impacts in the case of an RIC transition remaining in a high state, while SECP and HUMR were found to have significantly negative impacts. The results implied that the implementation of intellectual property administrative protection and the development of tertiary industries are likely to increase the probability of having a lock-in effect of RIC in a high state compared to the effects of secondary industries development and human capital accumulation, which may further assist RIC development and prevent the occurrence of lock-in and path-dependent effects.

\section{Conclusions and Implications}

By applying the HMM, this study endeavored to construct a transitional model for RIC in China and extensively explored the dynamic nature of RIC. The research results unveiedl three findings. (1) The features of RIC across regions in China can be categorized into three dynamic states (i.e., low, medium, and high states). This finding was consistent with previous studies that highlighted a significant disparity in RIC in China [6]. (2) The development of RIC has different transition process across regions and over time. Only three regions experienced all the three states of RIC during the sample period, while the rest only experienced one or two states of RIC. (3) The heterogeneous effects of innovation subject and innovation environment on RIC in different development states were observed, thus providing a more comprehensive and detailed view to ecent studies that have merely suggested that determinants in innovation subjects and innovation environments may generally enhance RIC $[6,51,67]$. For example, in the regions where the RIC is at a medium or above level, the improvement of enterprise innovation participation (innovation subject) was found to help reduce the passive effect of path-dependence and then promote RIC. When the RIC is in a medium state, the administrative protection and judicial protection of intellectual property (innovation environment) were found to be favorable to the transition of an RIC from a medium state to a high state.

This study provides two theoretical implications. (1) Grounded on the dynamic nature of RIC [29], this study is one of the pioneers in applying the HMM to investigate the transition states of RIC and thus reveal how an RIC evolves. The research results provide useful knowledge to the literature of RIC in two ways. On the one hand, the dynamic model applied in this study greatly complements prior studies that mainly investigated the features of RIC from the static perspective [11,27]; on the other hand, the data fitting method of the HMM employed in this study demonstrates a reliable model estimation of identifying the dynamic states of RIC [31]. Thus, this study has extended the application of the HMM to the field of RIC. (2) According to the authors' best knowledge, this study is also one of the early attempts to extensively explore the heterogeneous effects of the determinants of RIC state transitions using a dynamic model. In other words, this study contributes to the literature of RIC determinants and highlights that the effects of determinants on RIC may vary across states.

The research results provide several implications for policymakers to design sustainable development strategies and motivate technological innovation at the regional level in China and worldwide. Based on the differences and connections between regions, policymakers need to construct the support system of their regional sustainable development strategy from the perspective of innovation subject and environment. First, there is no one-size-fits-all solution to improve RIC for all regions; the findings defined three states of the RIC, thus providing guidelines to policymakers in identifying the state of RIC under their jurisdiction. It also would be wise for policymakers to subdivide innovation policies with full consideration of the disparity in RIC across different regions [68,69]. Second, the results provide a comprehensive understanding regarding the heterogeneous effects of the determinants in each scenario of RIC transitions, thus offering a roadmap for designing policies based on the current state of region and goals set for RIC development and innovation sustainability. For example, for regions a with low RIC, policymakers 
should promote the transition of the RIC state from a low state to a medium state by allocating recourse on critical determinants (e.g., the interaction between enterprises and universities, administration protection, and the development of secondary industry) [24]. Finally, the new economic geographical pattern under the current epidemic COVID-19 (Corona Virus Disease in 2019) situation promotes the sustainable development strategy of regional innovation. Our research provides a detailed scenario analysis for establishing potential theoretical frameworks in several fields, such as innovation resource integration and regional synergetic development.

There were some limitations to this study. First, the panel data in this research were collected in China, so future research should be cautious applying the results to other regions with different cultures, institutional structures, and geographic features. Second, this research was conducted at the regional level and provided useful guidance for urban innovation. Future research may focus on the dynamic transitions of innovation capacity using city data [70], so there is an urgent need for harmonized data at the more subdivided level. Third, this study endeavored to precisely measure the concepts of RIC based on the present literature. However, due to convention and the limitation of data availability, the validity of the proxy variables employed in this study must be tested by more empirical research in the future.

Author Contributions: S.L. and X.-Y.X. conceived of this study and participated in the design, administration of the study, and performed the data analysis. K.Z. and X.-Y.X. drafted the manuscript. K.Z., X.-Y.X., Q.L. and L.-M.X. revised the manuscript at several stages of the writing process. All authors have read and agreed to the published version of the manuscript.

Funding: This work was supported by the National Social Science Foundation of China [19CGL066], the Social Science Foundation of Shaanxi [2019D035], and the Soft Science Research Plan Project of Shaanxi [2019KRM161].

Data Availability Statement: The datasets used and/or analysed during the current study are available from the corresponding author on reasonable request.

Conflicts of Interest: The authors declare no conflict of interest.

\section{References}

1. Schiuma, G.; Lerro, A. Knowledge-based capital in building regional innovation capacity. J. Knowl. Manag. 2008, 12, 121-136. [CrossRef]

2. Cooke, P.; Uranga, M.G.; Etxebarria, G. Regional innovation systems: Institutional and organizational dimensions. Res. Policy 1997, 26, 475-491. [CrossRef]

3. Zhao, K.; Zhang, Y.; Zhao, J.; Li, X. Understanding Contributions of the Creative Class to Sustainable Economic Growth in China. Sustainability 2020, 12, 1304. [CrossRef]

4. Han, U.; Asmild, M.; Kunc, M. Regional R\&D Efficiency in Korea from Static and Dynamic Perspectives. Reg. Stud. 2016, 50, 1170-1184. [CrossRef]

5. Colglazier, W. Sustainable development agenda: 2030. Science 2015, 349, 1048-1050. [CrossRef]

6. Aryal, G.R.; Mann, J.; Loveridge, S.; Joshi, S. Drivers of differences in inventiveness across urban and rural regions. J. Urban Aff. 2020, 86, 1-18. [CrossRef]

7. Liu, X.; White, S. Comparing innovation systems: A framework and application to China's transitional context. Res. Policy 2001, 30, 1091-1114. [CrossRef]

8. Romer, P.M. Endogenous Technological Change. J. Political Econ. 1990, 98, S71-S102. [CrossRef]

9. Porter, M.E. The Competitive Advantage of Nations; Macmillan: London, UK, 1990; ISBN 0333518047.

10. Nelson, R.R. National Innovation Systems: A Comparative Analysis; Oxford University Press: Oxford, NY, USA, 1993; ISBN 0195076176.

11. Furman, J.L.; Porter, M.E.; Stern, S. The determinants of national innovative capacity. Res. Policy 2002, 31, 899-933. [CrossRef]

12. Du, W.; Li, M. Government support and innovation for new energy firms in China. Appl. Econ. 2019, 51, 2754-2763. [CrossRef]

13. Zhao, K.; Zhang, Y.; Zhao, J. Exploring the Complexity of Location Choices of the Creative Class in Europe: Evidence from the EU Labor Force Survey 1995-2010. Sustainability 2020, 12, 1687. [CrossRef]

14. Furman, J.L.; Hayes, R. Catching up or standing still? Res. Policy 2004, 33, 1329-1354. [CrossRef]

15. Hagedoorn, J.; Cloodt, M. Measuring innovative performance: Is there an advantage in using multiple indicators? Res. Policy 2003, 32, 1365-1379. [CrossRef] 
16. Hitt, M.A.; Hoskisson, R.E.; Johnson, R.A.; Moesel, D.D. The Market for Corporate Control and Firm Innovation. Acad. Manag. J. 1996, 39, 1084-1119. [CrossRef]

17. Mendoza-Silva, A. Innovation capability: A systematic literature review. EJIM 2020. Ahead of Print. [CrossRef]

18. Guan, J.; Liu, S. Comparing regional innovative capacities of PR China based on data analysis of the national patents. Int. J. Technol. Manag. 2005, 32, 225. [CrossRef]

19. Xiao, Z.; Du, X.; Wu, C. Regional Difference and Evolution and Convergence of Innovation Capability in China: Research on Space and Factorial Levels. Sustainability 2017, 9, 1644. [CrossRef]

20. Wang, X.; Fang, H.; Zhang, F.; Fang, S. The Spatial Analysis of Regional Innovation Performance and Industry-UniversityResearch Institution Collaborative Innovation-An Empirical Study of Chinese Provincial Data. Sustainability 2018, 10, 1243. [CrossRef]

21. Chen, K.; Kou, M. Staged efficiency and its determinants of regional innovation systems: A two-step analytical procedure. Ann. Reg. Sci. 2014, 52, 627-657. [CrossRef]

22. Leamer, E.E.; Storper, M. The Economic Geography of the Internet Age. J. Int. Bus. Stud. 2001, 32, 641-665. [CrossRef]

23. Proksch, D.; Haberstroh, M.M.; Pinkwart, A. Increasing the national innovative capacity: Identifying the pathways to success using a comparative method. Technol. Forecast. Soc. Chang. 2017, 116, 256-270. [CrossRef]

24. Li, T.; Fu, M.; Fu, X. Regional technology development path in an open developing economy: Evidence from China. Appl. Econ. 2013, 45, 1405-1418. [CrossRef]

25. Wei, Y.; Zhang, H.; Wei, J. Patent elasticity, R\&D intensity and regional innovation capacity in China. World Pat. Inf. 2015, 43, 50-59. [CrossRef]

26. Tian, X.; Wang, J. Research on the Disequilibrium Development of Output of Regional Innovation Based on R\&D Personnel. Sustainability 2018, 10, 2708. [CrossRef]

27. Li, X. China's regional innovation capacity in transition: An empirical approach. Res. Policy 2009, 38, 338-357. [CrossRef]

28. Prajogo, D.I.; Ahmed, P.K. Relationships between innovation stimulus, innovation capacity, and innovation performance. RED Manag. 2006, 36, 499-515. [CrossRef]

29. Kuokkanen, A.; Uusitalo, V.; Koistinen, K. A framework of disruptive sustainable innovation: An example of the Finnish food system. Technol. Anal. Strateg. Manag. 2019, 31, 749-764. [CrossRef]

30. Blundell, R.; Griffith, R.; van Reenen, J. Dynamic Count Data Models of Technological Innovation. Econ. J. 1995, 105, 333-344. [CrossRef]

31. Barragán-Ocaña, A.; Reyes-Ruiz, G.; Olmos-Peña, S.; Gómez-Viquez, H. Approach to the identification of an alternative technological innovation index. Scientometrics 2020, 122, 23-45. [CrossRef]

32. Chen, K.; Kenney, M. Universities/Research Institutes and Regional Innovation Systems: The Cases of Beijing and Shenzhen. World Dev. 2007, 35, 1056-1074. [CrossRef]

33. Yang, X.; Zhang, Z.; Luo, W.; Tang, Z.; Gao, X.; Wan, Z.; Zhang, X. The Impact of Government Role on High-Quality Innovation Development in Mainland China. Sustainability 2019, 11, 5780. [CrossRef]

34. Hou, J.; Chen, J.; Song, H.; Wang, G. Are Non-R\&D Innovation Activities Actually Effective for Innovation Sustainability? Empirical Study from Chinese High-Tech Industry. Sustainability 2019, 11, 174. [CrossRef]

35. Ponds, R.; Oort, F.V.; Frenken, K. Innovation, spillovers and university-industry collaboration: An extended knowledge production function approach. J. Econ. Geogr. 2010, 10, 231-255. [CrossRef]

36. Ponsiglione, C.; Quinto, I.; Zollo, G. Regional Innovation Systems as Complex Adaptive Systems: The Case of Lagging European Regions. Sustainability 2018, 10, 2862. [CrossRef]

37. Grossman, G.M.; Edwin, L.C.L. International protection of intellectual property. Am. Econ. Rev. 2004, 94, 1635-1653. [CrossRef]

38. Sleuwaegen, L.; Boiardi, P. Creativity and regional innovation: Evidence from EU regions. Res. Policy 2014, 43, 1508-1522. [CrossRef]

39. Lei, J.; Liu, Y.; Qi, Y.; Zhang, Q. 40 Years of Technological Innovation in China: A Review of the Four-Stage Climbing Track. J. Ind. Intg. Mgmt. 2019, 04, 1950008. [CrossRef]

40. Robert, C.P.; Celeux, G.; Diebolt, J. Bayesian estimation of hidden Markov chains: A stochastic implementation. Stat. Probab. Lett. 1993, 16, 77-83. [CrossRef]

41. Bartolucci, F.; Pandolfi, S.; Pennoni, F. LMest: An R Package for Latent Markov Models for Longitudinal Categorical Data. J. Stat. Soft. 2017, 81, 1-38. [CrossRef]

42. Altman, R.M. Mixed Hidden Markov Models. J. Am. Stat. Assoc. 2007, 102, 201-210. [CrossRef]

43. Rydén, T.; Teräsvirta, T.; Åsbrink, S. Stylized Facts of Daily Return Series and the Hidden Markov Model. J. Appl. Econom. 1998, 13, 217-244. [CrossRef]

44. Netzer, O.; Lattin, J.M.; Srinivasan, V. A Hidden Markov Model of Customer Relationship Dynamics. Mark. Sci. 2008, 27, 185-204. [CrossRef]

45. Hamilton, J.D. A New Approach to the Economic Analysis of Nonstationary Time Series and the Business Cycle. Econometrica 1989, 57, 357. [CrossRef]

46. Lee, K.; Go, D.; Park, I.; Yoon, B. Exploring Suitable Technology for Small and Medium-Sized Enterprises (SMEs) Based on a Hidden Markov Model Using Patent Information and Value Chain Analysis. Sustainability 2017, 9, 1100. [CrossRef] 
47. Chen, W.; Wei, X.; Zhu, X. Engaging Voluntary Contributions in Online Communities: A Hidden Markov Model. Mis. Q. 2018, 42, 83-100. [CrossRef]

48. Singh, P.V.; Tan, Y.; Youn, N. A Hidden Markov Model of Developer Learning Dynamics in Open Source Software Projects. Inf. Syst. Res. 2011, 22, 790-807. [CrossRef]

49. Franco, C.; Leoncini, R. Measuring China's innovative capacity: A stochastic frontier exercise. Econ. Innov. New Technol. 2013, 22, 199-217. [CrossRef]

50. Buesa, M.; Heijs, J.; Baumert, T. The determinants of regional innovation in Europe: A combined factorial and regression knowledge production function approach. Res. Policy 2010, 39, 722-735. [CrossRef]

51. Wang, J. Innovation and government intervention: A comparison of Singapore and Hong Kong. Res. Policy 2018, 47, 399-412. [CrossRef]

52. Hu, M.-C.; Mathews, J.A. National innovative capacity in East Asia. Res. Policy 2005, 34, 1322-1349. [CrossRef]

53. Gómez-Antonio, M.; Fingleton, B. Regional productivity variation and the impact of public capital stock: An analysis with spatial interaction, with reference to Spain. Appl. Econ. 2012, 44, 3665-3677. [CrossRef]

54. Rubashkina, Y.; Galeotti, M.; Verdolini, E. Environmental regulation and competitiveness: Empirical evidence on the Porter Hypothesis from European manufacturing sectors. Energy Policy 2015, 83, 288-300. [CrossRef]

55. Li, Y.; Tang, Y.; Wang, K.; Zhao, Q. Environmental Regulation and China's Regional Innovation Output-Empirical Research Based on Spatial Durbin Model. Sustainability 2019, 11, 5602. [CrossRef]

56. Cappelli, R.; Czarnitzki, D.; Doherr, T.; Montobbio, F. Inventor mobility and productivity in Italian regions. Reg. Stud. 2019, 53, 43-54. [CrossRef]

57. Viterbi, A. Error bounds for convolutional codes and an asymptotically optimum decoding algorithm. IEEE Trans. Inform. Theory 1967, 13, 260-269. [CrossRef]

58. Horii, R.; Iwaisako, T. Economic Growth with Imperfect Protection of Intellectual Property Rights. J. Econ. 2007, 90, 45-85. [CrossRef]

59. Derbyshire, J.; Gardiner, B.; Waights, S. Estimating the capital stock for the NUTS2 regions of the EU27. Appl. Econ. 2013, 45, 1133-1149. [CrossRef]

60. Lundvall, B.A.; Johnson, B.o.r.; Andersen, E.S.; Dalum, B. National systems of production, innovation and competence building. Res. Policy 2002, 31, 213. [CrossRef]

61. Asheim, B.; Vang, J. Regional innovation systems in Asian countries: A new way of exploiting the benefits of transnational corporations. Innovation 2006, 8, 27-44. [CrossRef]

62. Mai, J.; Stoyanov, A. Anti-foreign bias in the court: Welfare explanation and evidence from Canadian intellectual property litigations. J. Int. Econ. 2019, 117, 21-36. [CrossRef]

63. Choi, I. Unit root tests for panel data. J. Int. Money Financ. 2001, 20, 249-272. [CrossRef]

64. Claro, S. Why does China protect its labour-intensive industries more? Econ. Transit. 2006, 14, 289-319. [CrossRef]

65. Chirico, F.; Criaco, G.; Baù, M.; Naldi, L.; Gomez-Mejia, L.R.; Kotlar, J. To patent or not to patent: That is the question. Intellectual property protection in family firms. Entrep. Theory Pract. 2020, 44, 339-367. [CrossRef]

66. Park, W.G. International patent protection: 1960-2005. Res. Policy 2008, 37, 761-766. [CrossRef]

67. Buesa, M.; Heijs, J.; Martínez Pellitero, M.; Baumert, T. Regional systems of innovation and the knowledge production function: The Spanish case. Technovation 2006, 26, 463-472. [CrossRef]

68. Zeng, J.; Wu, W.; Liu, Y.; Huang, C.; Zhao, X.; Liu, D. The local variations in regional technological evolution: Evidence from the rise of transmission and digital information technology in China's technology space, 1992-2016. Appl. Geogr. 2019, 112, 102080. [CrossRef]

69. Li, D.; Wei, Y.D.; Miao, C.; Wu, Y.; Xiao, W. Innovation, Network Capabilities, and Sustainable Development of Regional Economies in China. Sustainability 2019, 11, 4770. [CrossRef]

70. Carlino, G.A.; Chatterjee, S.; Hunt, R.M. Urban density and the rate of invention. J. Urban Econ. 2007, 61, 389-419. [CrossRef] 